\title{
Editorial: Flood Susceptibility and Risk Maps as a Crucial Tool to Face the Hydrological Extremes in Developing Countries: Technical and Governance Aspects Linked by a Participatory Approach
}

\author{
Rosanna Bonasia ${ }^{1 *}$, Luis $\mathrm{Cea}^{2}$ and Umberto Fratino ${ }^{3}$ \\ ${ }^{1}$ CONACYT - Instituto Politécnico Nacional ESIA UZ, Mexico City, Mexico, ${ }^{2}$ Department of Civil Engineering, Universidade da \\ Coruña Environmental and Water Engineering Group, A Coruña, Spain, ${ }^{3}$ DICATECh, Politecnico di Bari, Bari, Italy
}

Keywords: flood susceptibility, participatory approach, risk maps, hydrological extremes, developing countries

Editorial on the Research Topic

Flood Susceptibility and Risk Maps as a Crucial Tool to Face the Hydrological Extremes in Developing Countries: Technical and Governance Aspects Linked by a Participatory Approach

\section{OPEN ACCESS}

Edited and reviewed by: Carmine Galasso,

University College London, United Kingdom

${ }^{*}$ Correspondence: Rosanna Bonasia rbonasia@conacyt.mx

Specialty section: This article was submitted to Geohazards and Georisks,

a section of the journal

Frontiers in Earth Science

Received: 17 December 2021 Accepted: 31 January 2022 Published: 25 February 2022

Citation: Bonasia R, Cea L and Fratino U (2022) Editorial: Flood Susceptibility and Risk Maps as a Crucial Tool to Face the Hydrological Extremes in Developing Countries: Technical and Governance Aspects Linked by a

Participatory Approach. Front. Earth Sci. 10:838172. doi: 10.3389/feart.2022.838172
Floods have been the subject of repeated alarming news in 2021, for their recurrence has increased in frequency all over the world with very high-cost consequences in terms of economic losses and human suffering. Floods represent one of the most common and severe natural disasters, capable of disrupting people's livelihoods around the world. Their effects are particularly evident in low-income countries, where the lack of adequate infrastructure, limited know-how and the scarcity of monitoring systems, make the situation even more serious.

Rentschler and Salhab (2020) in their recent study of 189 countries' exposure to floods and poverty, find that $19 \%$ of the world's population is in conditions of direct exposure to risk during flood events that occur once every 100 years. Of this percentage, the majority of the population at risk is concentrated in developing countries, most located in sub-Saharan Africa and in South and East Asia. The number of people exposed to flood risk has increased enormously in recent decades, surpassing, already in 2020, the estimates made for 2050 (Jongman et al., 2012; Rentschler and Salhab, 2020). This situation is due to various factors, among which climate change plays a fundamental role. Emanuel (2013) estimates that the frequency of tropical cyclones is increasing by $10-40 \%$ during the first three quarters of the twenty-first century, while their intensity is estimated at an increase of about $15 \%$ as calculated by Hong et al. (2021). However, it is not only major and infrequent floods that pose a danger to exposed populations, even less rare and minor events can jeopardize particularly vulnerable populations (Hoeppe, 2016). The increase in susceptibility to flooding is also determined by the increase in population and urbanization of high-risk areas. The uncontrolled urbanization determines a change in land use which causes a direct influence on the increase in surface runoff levels (Huang et al., 2014; Liu et al., 2019).

In the light of these evidence, this Research Topic wanted to emphasize the importance of local strategies in managing flood risk, in order to increase public awareness and preparedness. 
Scaini et al. focus attention on the importance of citizen involvement in flood risk management plans. Their participation in the development of local inputs for the measures to be taken to deal with the risk of flooding is still very limited, given the difficulty of quantifying the perceived risk because it is based on personal opinions. However, authors point out that perceived risks may correspond to evidence-based data and in their work, they present a project questionnaire which aims to characterize the perception of flood risk and its spatial distribution at the basin scale. The proposal was tested on the Tagliamento river, in Italy, one of the last free-flowing rivers in Western Europe and the last free-flowing Alpine river. The questionnaire was tested for assess risk perception and compare it to available hazard/risk maps. Results show that perceived risk is in good agreement with existing hazard and risk assessments. Furthermore, the population has shown a strong interest in being involved in handling the risk debate, expressing the belief that risk reduction is compatible with river conservation and both of these objectives should be achieved together.

The concepts of conservation of natural areas and a participatory approach in support of decision makers are also developed by Scrieciu et al. who analyze the potential of naturebased solutions (NBS) to deal with the risk of flooding. The authors start from the basic hypothesis that the barriers posed to the wide diffusion of NBS are mainly due to the lack of involvement and knowledge integration of stakeholders during the design phases of NBS. For this reason, they propose a combined approach based on the integration of Fuzzy Cognitive Maps (FCM), Hydraulic Modeling (HM), and participatory Bayesian Belief Networks (BBN) aiming to facilitate the stakeholders' engagement and the knowledge integration process in NBS design and assessment. The proposal has been applied to the Lower Danube demo site, with the aim also of supporting the process of the Potelu Wetland restoration. The proposed methodology aims to demonstrate the suitability of the BBN, in support of FCM and HM, to evaluate the effectiveness of NBS in addressing

\section{REFERENCES}

Emanuel, K. A. (2013). Downscaling CMIP5 Climate Models Shows Increased Tropical Cyclone Activity over the 21st century. Proc. Natl. Acad. Sci. 110, 12219-12224. doi:10.1073/pnas.1301293110

Hoeppe, P. (2016). Trends in Weather Related Disasters - Consequences for Insurers and Society. Weather Clim. Extremes 11, 70-79. doi:10.1016/j.wace. 2015.10.002

Hong, C.-C., Tsou, C.-H., Hsu, P.-C., Chen, K.-C., Liang, H.-C., Hsu, H.-H., et al. (2021). Future Changes in Tropical Cyclone Intensity and Frequency over the Western North Pacific Based on 20-km HiRAM and MRI Models. J. Clim. 34, 2235-2251. doi:10.1175/jcli-d-20-0417.1

Huang, C.-J., Hsu, M.-H., Teng, W.-H., and Wang, Y.-H. (2014). The Impact of Building Coverage in the Metropolitan Area on the Flow Calculation. Water 6, 2449-2466. doi:10.3390/w6082449

Jongman, B., Ward, P. J., and Aerts, J. C. J. H. (2012). Global Exposure to River and Coastal Flooding: Long Term Trends and Changes. Glob. Environ. Change 22 (4), 823-835. doi:10.1016/j.gloenvcha.2012.07.004

Liu, S., Huang, S., Xie, Y., Wang, H., Leng, G., Huang, Q., et al. (2019). Identification of the Non-stationarity of Floods: Changing Patterns, Causes, and Implications. Water Resour. Manage. 33, 939-953. doi:10.1007/s11269-018-2150-y the risk of floods. The methodology presented can be applied in other areas and represents a useful tool for establishing the active involvement of stakeholders in the evaluation and implementation of NBS.

Finally, Mokkenstorm et al. present a methodology for flood detection based on the use of Passive Microwave Remote Sensing (PMRS). The authors stress the importance of the application of remote sensing satellite data, particularly in ungauged river basins of developing countries, due to their low cost and low maintenance. Particularly, this study focuses on determining whether PMRS images can actually be used for the prevention of damage caused by floods and the cases of application are two small-scale basins in Malawi. Two indices were analyzed: the $m$ index, expressed as the magnitude relative to the average flow, and $a n$ index that takes into account an additional wet calibration cell. Results, compared with the discharge estimates of the Global Flood Awareness System, show that the detected flood levels are very accurate, demonstrating that the methodology is valid and particularly useful for monitoring rivers of data-scarce areas.

In summary, this Research Topic wants to draw attention to two points of reflection: 1) The need to involve stakeholders at all levels in the planning of actions aimed at reducing the risks associated with floods is preponderant, given the considerable increase in urban settlements in high-risk areas of developing countries. 2) Likewise, we hope that new lines of research will open up to explore innovative solutions that help in risk management without having to resort to costly methods, which involve manpower or require continuous maintenance.

\section{AUTHOR CONTRIBUTIONS}

The authors are co-editors which organized this Research Topic, substantially, directly, and intellectually contributed to the work on this Research Topic and the manuscript and approved it for publication. All authors contributed to the article and approved the submitted version.

Rentschler, J., and Salhab, M. (2020). People in Harm's Way : Flood Exposure and Poverty in 189 Countries. Policy Research Working Paper: No. 9447. Washington, DC: World Bank. Available at: https://openknowledge. worldbank.org/handle/10986/34655 License: CC BY 3.0 IGO. (C) World Bank.

Conflict of Interest: The authors declare that the research was conducted in the absence of any commercial or financial relationships that could be construed as a potential conflict of interest.

Publisher's Note: All claims expressed in this article are solely those of the authors and do not necessarily represent those of their affiliated organizations, or those of the publisher, the editors and the reviewers. Any product that may be evaluated in this article, or claim that may be made by its manufacturer, is not guaranteed or endorsed by the publisher.

Copyright (c) 2022 Bonasia, Cea and Fratino. This is an open-access article distributed under the terms of the Creative Commons Attribution License (CC $B Y)$. The use, distribution or reproduction in other forums is permitted, provided the original author(s) and the copyright owner(s) are credited and that the original publication in this journal is cited, in accordance with accepted academic practice. No use, distribution or reproduction is permitted which does not comply with these terms. 